\title{
巨大内頸-眼動脈瘤治療の問題点
}

\author{
渋谷 正人, 鈴木善男, 中根 藤七 \\ 小倉 浩一郎，原田努，木野本 武久 \\ 景山 直 樹
}

\section{Direct Approach to Giant Carotid Ophthalmic Aneurysms}

\author{
Masato Shibuya, M. D., Yoshio Suzuki, M. D., Toshichi Nakane, M. D., \\ Koichiro Ogura, M. D., Tsutomu Harada, M. D., Takehisa Kinomoto, M. D., and \\ Naoki Kageyama, M. D.
}

Department of Neurosurgery, Nagoya University School of Medicine, Nagoya, Japan

Summary : Direct clipping was performed in two cases of giant ophthalmic $(30 \mathrm{~mm}$ in diameter, subopticochiasmal global type) aneurysms in the right side who presented with visual disturbances in both eyes. Case 2 showed a second small aneurysm in the left IC-ophthalmic region. Preoperatively collateral circulation and tolerance to ischemia were studied by the Allcock and Matas tests. Both cases were operated on by right frontotemporal craniotomy. The neck carotid arteries were prepared for temporary occlusion during which time the brain function was monitored by scalp EEG. An STA-MCA anastomosis was performed before aneurysm surgery in Case 2.

The optic canal was opened and the anterior clinoid processes, which were well developed and pneumatized in both cases, were meticulously removed subdurally with an air drill. The anterior clinoid process in Case 1 continued to the middle clinoid process forming a bony canal around $\mathrm{C} 3$, which made the situation even more difficult. The cavernous sinus had to be opened around $\mathrm{C} 3$ in both cases in order to obtain space for the clip blade in the proximal neck of the aneurysm. Further dissection of the aneurysm from the surrounding structures such as the contralateral IC, optic nerve and chiasm could only proceed after the aneurysm had been decompressed by puncture, after which fenestrated clips could be applied without difficulty. Only one fenestrated and angled clip was applied in Case 1. Three fenestrated clips were needed in tandem manner in order to close the neck in Case 2. Here a fourth straight clip was necessary in order to stop continuous oozing, probably from the space between the tandem clips.

\section{Key words :}

- carotid-ophthalmic aneurysm

- giant aneurysm

- operative approach 
Postoperatively Case 1 returned to her normal household activities. Case 2 was blinded in her right eye and showed dense left hemiparesis, for which she is receiving rehabilitation at four months after the surgery. CT showed an infarction in the territory of the right anterior choroidal artery.

Discussions are presented about 1) choice of treatment, direct or IC occlusion with bypass surgery ; 2) ischemia monitors and brain protection during temporary occlusion of the IC; 3 ) importance of opening the cavernous sinus in order to obtain the proximal neck of the aneurysm ; 4) importance of protection of the posterior communicating, anterior choroidal and perforating arteries, especially when fenestrated and angled clips are applied.

\section{はじめに}

内頸一眼動脈瘤は巨大動脈瘤, 両側性または多発性動脈瘤 の頻度が高く，女性に多いなどの特徵を有し，トルコ鞍， 海綿静脈洞, 視神経などに囲まれているため, しばしば治 療が困難な動脈瘤の1つである。これを直達手術で行うか 間接的に頸動脈閉塞十バイパス手術にするかは，側副血行 の状態, 動脈瘤の大きさ, ネックなどの形態的特徵, 破 裂の危険性, 両眼の視力障害の程度などのさまざまな要因 を検討し, 決定されるべきものである. われわれは最近, 視力障害で発症した 2 例の内頸一眼動脈巨大動脈瘤 (giant suboptico-chiasmal or global type $)^{9)}$ に执いて直達手術を 行ったが，その際問題となった点をここに取り上げてみた.

\section{症例}

〈症 例 1〉45歳女性. 3 年来右失明, CT, 血管写にて右 内頸動脈一眼動脈起始部に長径 $31 \mathrm{~mm}$ の巨大動脈瘤があり, 左からの側副血行はないが Allcock テストにより後交通 動脈を介する側副血行は存在し, Matas テストは30分間無 症状であった。

手術：頭皮脳波電極設置, 頸部頸動脈を確保したのち, STA の前頭, 頭頂両枝を含む大きな頭皮弁にて右前側 頭

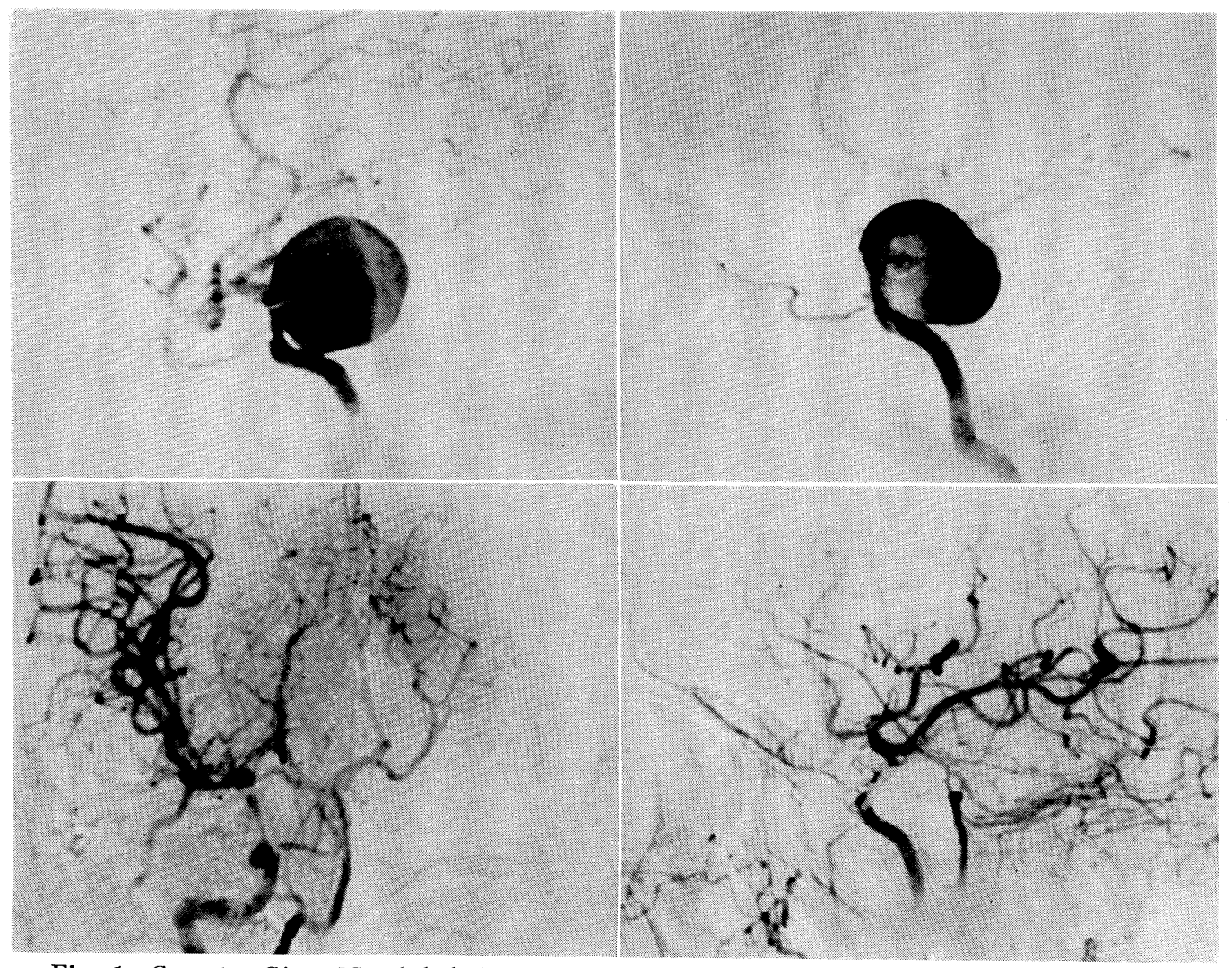

Fig. 1 Case 1. Giant IC-ophthalmic aneurysm, preoperative (upper figures) and postoperative (lower figures) angiography. 


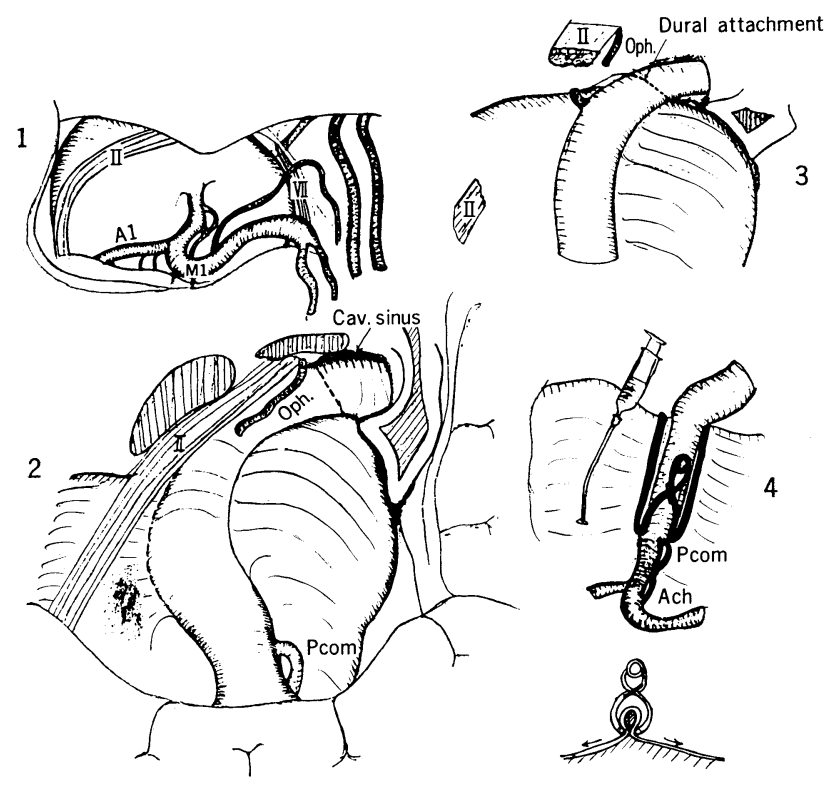

Fig. 2 Operative sketches in Case 1. Notice that 1) the large anterior clinoid process continued to the base of the skull $(2,3), 2)$ clipping left only a small caliber of IC due to extensive adhesion of the aneurysm wall to the skull base (4), 3) straightening of the $\mathrm{C}_{2-3}$ curvature after clipping (4).

開頭を行った．動脈瘤は Fig. 2 に示すごとく視野全体を占 め, $\mathrm{C}_{2-1}$ はあたか子花火の導火線のように見光た。視神経 管壁, 前床突起をドリルで削除し, 海綿静脈洞の硬膜を, $\mathrm{C}_{3}$ を取り囲んでいる部分で開き，出血をオキシセル，ビオ ボンドで止めながらネック近位部の剝離を進めた。前床突 起は長く，その下面は中床突起と骨性㽷合し， C 3 をとりま く foramen を形成していた。この部位では $C_{3}$ と動脈瘤壁 の谷間でドリルを使わざるを得ず，頸部 IC 遮断後でも視 野が狭く，困難をきわめた。この部分は血管写上は動脈瘤 ネックよりははるかに中枢部で，十分吵間があるように見 えたが，実際には $\mathrm{C}_{3}$ と動脈瘤壁は強固に癒着しており, ク リップの先端を通すためにはこの癒着の剝離が必須であっ た. さらにC 3 の前壁を剝離する際に視神経と眼動脈を切断 した. 動脈瘤を一時的に trapping 乙, 穿刺, 減圧後, 穴 開き直角（杉田\#43）のクリップを掛けたが，この際動脈 瘤壁の周辺への癒着は強固でクリップがあたかもテントの 先端を摘むような形になってしまったが内腔は保たれた (Figs. 1, 2).

術後経過：術後一過性の左半身不全マヒと左耳側半盲が 出現したが，マヒは改善し, 半年後の現在患者は家庭の主 婦として働いている. CT では Heubner 動脈領域の低吸 収域を認め, IC temporary occlusion の際の脳へラの掛 け方が問題と思われた。また左耳側半盲についてはCTで 現われない程度の前脈絡叢動脈領域の梗塞か, 視交叉への 障害が疑われた。
〈症例 2〉54藏女性. 両側網膜剝離, 右虚血性視神経障 害のための諸検査の結果, 右 $\mathrm{C}_{2}$ 亿長径 $30 \mathrm{~mm}$ の巨大動脈 瘤, 対側の左 $\mathrm{C}_{2}$ 飞小動脈瘤が発見された。視力は右 0.1 , 左 0.3 と悪く, 両側性の動脈瘤であり, 将来左側を処理す る必要性も考光直達手術の適応之考光た。血管写上の左右 の交通は良好であり, Matas テストは20分間無症状であっ

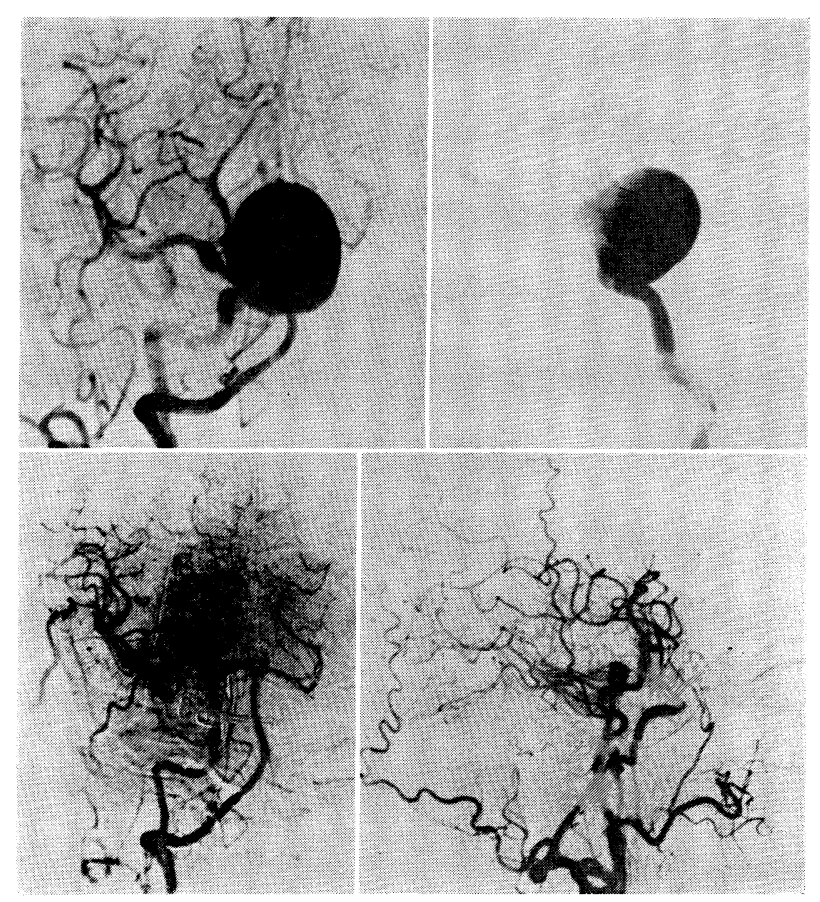

Fig. 3 Case 2. Giant IC-ophthalmic aneurysm, preoperative (upper figures) and postoperative (lower figures) angiography. Patent STA-MCA anastomosis is seen in the lower figures.

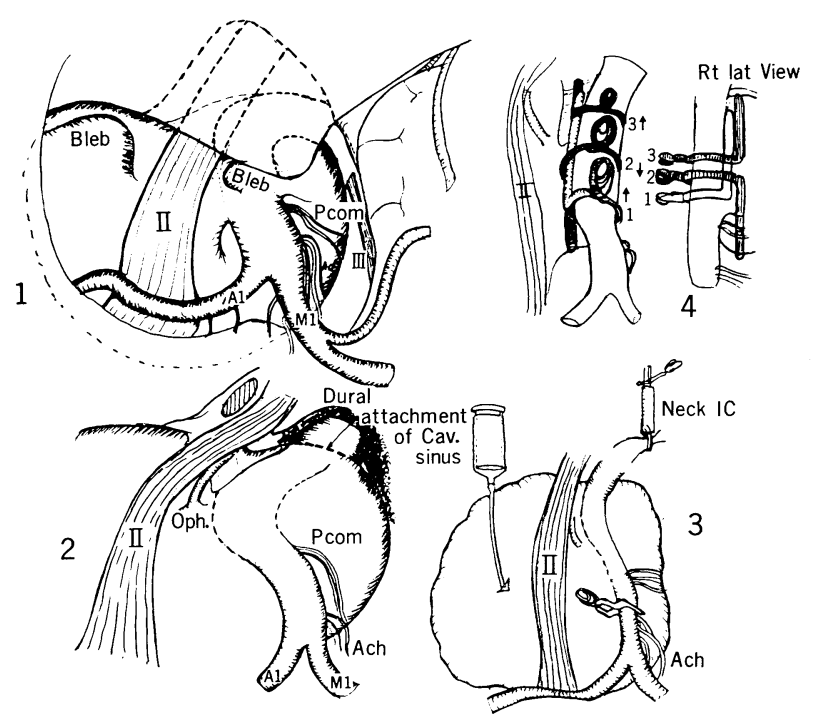

Fig. 4 Operative sketches in Case 2. Notice that the ophthalmic artery originates from the aneurysm. Smaller bleb on IC was coagulated. 
たが，Allcock テストによる後交通動脈を介する血流は認 められなかった。

手術：頭皮脳波電極を設置し，頸部頸動脈を確保したの ち，右前側頭開頭を行いSTA-MCA 吻合術を行った。動 脈瘤は 2 か所に blebを有し，今にも破れそうなかっこう をしていた。症例 1 と同様にドリルで視神経管を開放し， 前床突起を大々的に削除し, 海綿静脈洞を開き動脈瘤近位 部のC 3 周囲を剝離した。眼動脈は IC から離れた位置で動 脈瘤から直接出ておりこれを残してはクリッピング不可能 と判断し，凝固切断した，動脈瘤を一時的に trapping し， これに穿刺, 減圧し, 後交通動脈, 前脈絡叢動脈を避けて 穴開きクリッブを 3 個掛けた(Figs. 3,4)。ところが完全に クリップがかかっていると思われるにもかかわらず穿刺部 位からの oozing は止まらず穿刺部位を中心に第 4 の直ク リップにて摘み止血した。 blebの1つは穴開きクリップの 手前, IC 側にきたため，これを凝固縮小せしめた。なお IC 一時遮断時に頭皮脳波には著明な左右差は認めなかった。

術後経過：術後血管写にて右内頸動脈腔は保たれ血管吻 合部もよく開存しているが，CT 上前脈絡叢動脈領域の梗 塞を認め，左半身不全マヒと右失明をきたし，4 か月後の 現在リハビリを行っている.

\section{考案}

以上 2 例の経過をふり返ってみると第 1 例は残された左 眼視野が術前の傍中心暗点から術後耳側半盲へと拡大し, 第 2 例では右視力が 0.1 から失明拉よび左半身不全マヒの 出現と，ともに動脈瘤破裂の危険は回避できたものの満足 すべき結果とはいいがたく，治療に関するより細かな検討 が必要と思われた，そこで内頸一眼動脈巨大動脈瘤の 治療 上考慮すべき問題点を Table 1 に掲げたが，そのうち特 に重要と思われるものについて述べる。

まず治療法の選択で頸動脈閉塞 ${ }^{4) 6)}$ か直達手術1) 2) 3) 5) 8) 9) かについては，われわれは以下のよらな理由から可能な限 り直達手術が望ましいと考光る。すなわち，1)頸動脈閉塞 では必ずしも動脈瘤の破裂は予防できず，実際に約 $10 \%$ の 破裂が報告されており ${ }^{6)}$ ，さらに対側の内頸動脈の血流増 加による他の動脈瘤の増大，破裂の危険が考学られる，2) 動脈血栓化に伴う塞栓症, 眼動脈虚血, さらに mass が減少 せず視力障害改善の可能性がより少ない。頸動脈を人為的 に閉塞するといらことは最後の手段にすべきで，特にわれ われの第 2 例のように対側の内頸動脈溜を将来手術しなけ ればならない可能性が強いときにはな特さらのことである.

バイパス手術は直達手術に和いても必要な場合があるが その適応を考えるうえで注意したいのは術前の (balloon) Matasテストによる虚血と直達手術中の内頸動脈遮断によ
Table 1 What to consider about a giant caratid ophthalmic aneurysm?

I. IC occlusion+bypass surgery

1) How to occlude IC : Balloon or ligation, one-step or gradual

2) Risk of rupture of the aneurysm

3) "Mass" lesion

4) Ischemic optic neuropathy

5) Problems about bypass surgery

II . Direct surgery

a. Radio-anatomical studies

1) Anatomical relationship between the aneurysm and carotid artery, optic nerve, cavernous sinus, sella turcica, ant. clinoid process studied by angiography, high resolution CT etc.

b. Prophylaxis of ischemia

1) Angiographic study of collateral circulation : Allcock, (Balloon) Matas tests

2) Bypass surgery : Needed?, When and how?

3) Ischemia monitors: EEG, ECoG, SEP, VEP, rCBF, Doppler etc.

4) Anticoagulation \& brain protection: Heparin Mannitol (Glycerol), Isoflurane, Barbiturates, Vit C \& E, Hydantoin, Steroids, Xylocain etc.

5) BP raising : to what extent?

c. Dissection and clipping

1) Secure proxymal IC : Cervical or intracranial

2) Opening of cavernous sinus: High head position

3) Puncture of the aneurysm, further dissection from contralateral optic nerve, chiasm, skul base etc.

4) Clipping without disturbing natural curvature along $\mathrm{C}_{2-3}$

5) Tandem clips with puncture : Oozing from space between clips

6) Clip reapplication : as few times as possible

7) Preserve ophthalmic, Pcom, Ach and perforating arteries

8) Evaluation by intraoperative angiography III. Intramural surgery : Detachable balloon, artificial thrombosis etc.

る虚血とは必ずしも同じではなく脳の retraction，血管の stretching の加わる術中虚血の方がはるかに程度が強いと 考えなければならない。術中頸動脈一時遮断の時間，脳一 ラの retractionの程度を決めるために虚血に対する種種の モニターが考学られるが，できたら術中脳血流測定と皮質 下の機能を知るために SEP などの測定が望ましい，今回 われわれは術中頭皮脳波のみを参照にしたが，2 例目に見 られたような前脈絡叢動脈領域の虚血は予知できなかった。

次に術中虚血, 特に頸動脈一時遮断の際の虚血に対する 治療として，われわれの2例を見る限り Duke Samson7) の言うようにヘパリンを使用すべきだったかもしれない. また sludging 予防剤, free radical scavenger 有効と 思われる。ささら血圧を高位に保つことも必要である。

次に動脈瘤剝離に関しては視神経管の開放, 前床突起の 削除はもちろん必要であるが，これらと IC，動脈瘤の位 置関係を high resolution CT にて十分把握しておく必要 が女る(Fig. 5)。症例 1 で見られたように前・中床突起が 骨性癒合して foramen を形成していたり，症例 2 のよう に前床突起が大きくて空洞を有するなどの特徵をあらかじ 

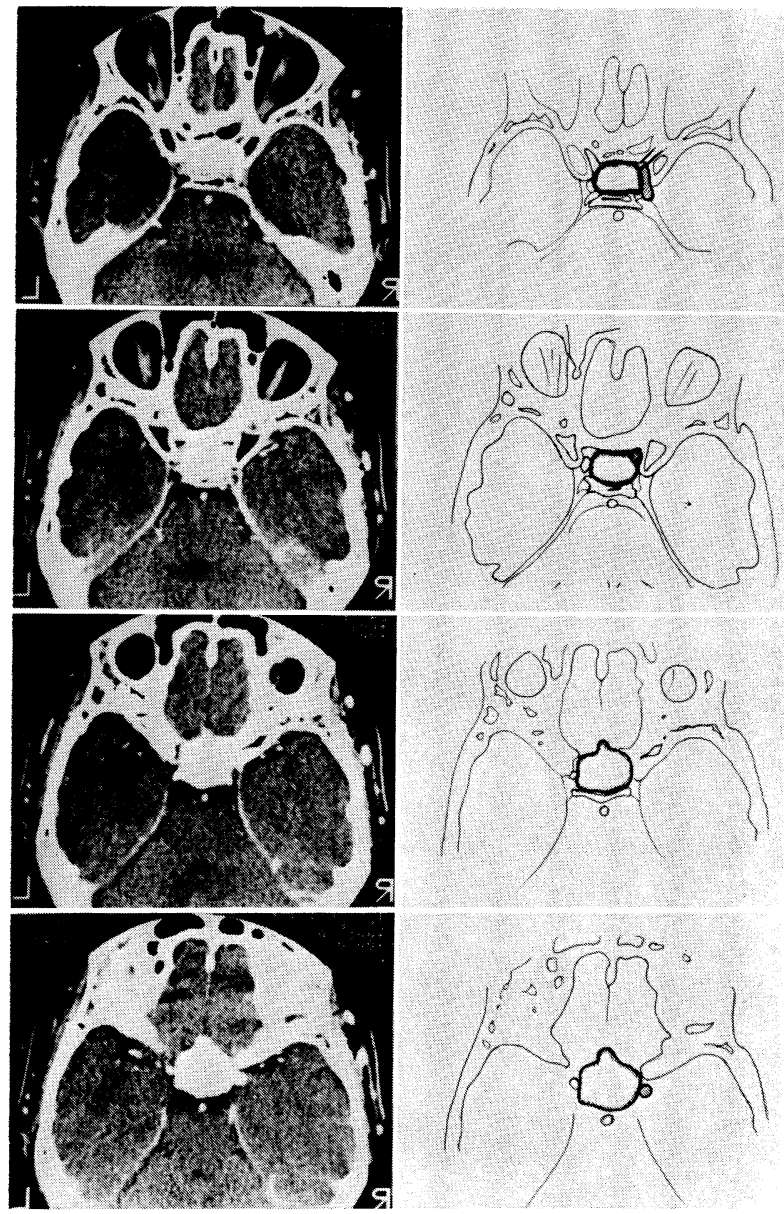

Fig. 5 High resolution enhanced CT in Case 2. Topographic orientations between the IC, aneurysm, anterior clinoid process and optic canal etc. can be obtained along the course of the IC from $\mathrm{C}_{5}$ (uppermost figure) to $\mathrm{C}_{1}$ (lowermost figure) which is shown as shaded circles.

め知っておくとドリル使用の際大いに役に立つ.

海綿静脈洞に関しては，血管写上動脈瘤ネックが明らか に眼動脈起始部より末梢にあり動脈瘤と $\mathrm{C}_{3}$ の間に隙さ間が あるように見光ても実際には両者が強固に癒着しているこ とがあり, 海綿静脈洞を開いて， C 3 を外側へ向かって剥離 する必要があるが，この際海綿静脈洞からの出血に対して， 頭位を十分高く保ち, Oxycel, Biobond, Thrombin など を出血部位につめながら剝離を進め, 穴開きクリップの両 方の先端がC 3 を越して閉じる空間を作らなければならない。

眼動脈が動脈瘤から直接出ている場合，これを温存する のは困難なことが多い。症例 2 で術前虚血性視神経障害と 診断されたのはこのような解剖学的状況にあったためとも 考えられる。ささて動脈瘤ネックが剥離できたところでクリ ップを掛けるが, この際動脈瘤を穿刺, 減圧しないと十分 クリップを掛けることがむずかしい。一方動脈瘤を穿刺, 減圧するとトルコ鞍, 視交叉, 対側の視神経, ICがよく見 えるようになるので，これらから動脈瘤壁をさらに豩離し，
少しでもクリップの手前にくる IC の内腔を多く取るよう な努力が必要で女る。この際穴開きクリップはバネ力が強 いので掛け直しの回数はできるだけ少なく(杉田)，さらに $\mathrm{C}_{2-3}$ の IC の自然の彎曲が保たれるようなクリップの掛け 方が望ましい(小林).

われわれの 2 例ともクリップ後同部の彎曲が直線化して 打り,術後ICの内腔が十分には保たれなかった原因の 1 つ と考えている。ささに穴開きクリップはその角度ゆえ，術 後，脳を戻したときに周辺の血管を圧迫する危険性が考兄 られ，特にここでは後交通動脈，前脈絡叢動脈への圧迫に 十分な注意を要する，クリッピングが十分かどらかは直視 下に見ただけでは不十分で，できたら術中血管写によって 確めることが望ましい。また動脈瘤穿刺後 tandem または piggy back clip を使用するときはクリップの重叔目から の oozing が止まらないことがあり，さらに体部を別の 1 本のクリップで挾むか，接着剤でシールする必要がある。

以上, 内頸一眼動脈巨大動脈瘤（global type）直達手術の 問題点を挙げてみたが，近い将来 detachable balloon, intramural surgery がさらに進歩すれば, これらの問題も 別の視点から再検討が必要であろら。眼動脈と交感神経の 関係は必ずしも明確ではないが，少なくともHorner 症候 群に関与する交感神経線維は海綿静脈洞内で IC を離れVI, $\mathrm{V}$ 脳神経に乗って毛様体神経節へいくようで, 今回の 2 例 とも，眼動脈切断後も瞳孔の变化などは認められなかった．

\section{文献}

1) Dolenc VV : A combined epi- and subdural direct approach to carotid-ophthalmic artery aneurysms. J Neurosurg 62 : 667-672, 1985

2) Drake CG : Giant intracranial aneurysms : Experience with surgical treatment in 174 patients. Clin Neurosurg $26: 12-95,1979$

3) Ferguson GG, Drake CG : Carotid-ophthalmic aneurysms: Visual abnormalities in 32 patients and the results of treatment. Surg Neurol 16:1-8, 1981

4) Gelber BR, Sundt TM Jr : Treatment of intracavernous and giant carotid aneurysms by combined internal carotid ligation and extra- to intracranial bypass. J Neurosurg $52: 1-10,1980$

5) Heros RC, Nelson PB, Ojemann RG, Crowell RM, DeBrun $\mathrm{G}$ : Large and giant paraclinoid aneurysms: Surgical techniques, complications, and results. Neurosurgery 12 : 153-163, 1983

6) Nishioka H: Report on the cooperative study of intracranial aneurysms and subarachnoid hemorrhage : Section VIII, Part 1. Results of the treatment on intracranial aneurysms by occlusion of the carotid artery in the neck. J Neurosurg 25:660-682, 1966

7) Samson DS : Comments at the International workshop on intracranial aneurysms, Tokyo, 1986

8) Sundt TM Jr, Piepgrass DG : Surgical approach to giant intracranial aneurysms. Operative experience with 80 cases. J Neurosurg 51: 731-742, 1979

9) Yasargil MG, Gasser JC, Hodosh RM, Rankin TV: Carotid-ophthalmic aneurysms : direct microsurgical approach. Surg Neurol $8: 155-165,1977$ 